\title{
Acidentes de Motocicletas e sua relação com o trabalho: revisão da literatura
}

\author{
Motorcycle accidents and its relation to work: a literature review
}

\author{
Ivan Dieb Miziara'; Carmen Silvia Molleis Galego Miziara²; Lys Esther Rocha ${ }^{3}$
}

DOI: http://dx.doi.org/10.11606/issn.2317-2770.v19i2p52-9 Miziara ID; Miziara CSMG; Rocha LE. Acidentes de Motocicletas e sua relação com o trabalho: revisão da literatura.
Saúde, Ética \& Justiça. 2014;19(2):52-9.

\begin{abstract}
RESUMO: Introdução: na última década, no Brasil, vem-se observando um importante aumento do número de acidentes envolvendo motocicletas, veículo que ganha cada vez mais aceitação e aprovação da população, por ser ágil e de baixo custo. Objetivo: o objetivo deste estudo foi, através de revisão da literatura, descrever os principais aspectos dos acidentes de trânsito com motocicletas e sua relação com o trabalho. Método: trata-se de estudo descritivo realizado por revisão de literatura nas principais bases de dados de livre acesso. Os critérios de inclusão foram artigos científicos e publicações dos últimos 10 anos, pricipalmente, com dados brasileiros ou de outros países. Os textos selecionados foram em português, inglês e espanhol e os descritores utilizados foram: motocicleta, acidente de trânsito, acidente de trabalho, epidemiologia, mortalidade e mortalidade ocupacional. Resultados: a motocicleta representa, no Brasil, um meio de transporte socialmente importante, especialmente para a classe trabalhadora, que a utiliza para transporte próprio ou como meio de prestação de serviços como mototaxi, motoboy ou motofrete. O perfil dos acidentados com uso de motocicletas tem, em geral, é do sexo masculino, jovem ( 20 a 30 anos), com baixa escolaridade e que veem no trabalho de motoboy ou mototaxi a oportunidade de se inserir no mercado de trabalho e de conseguir sustento para si e para a família. Os motociclistas trabalham principalmente no ramo de transporte de alimentos e para drogarias. Como fatores de risco, foram identificados: alta exposição a riscos de toda sorte (físicos, químicos, psicossociais); dirigir em situações de cansaço físico e mental, consumo prévio de álcool, jornadas expandidas horas diárias. Os motociclistas nem sempre possuíam registro em carteira profissional e em poucos casos foi emitida a comunicação de acidente de trabalho. Conclusão: são poucos os estudos realizados no Brasil que abordam os aspectos sobre o trabalho dos motociclistas. Entretanto, acreditamos que o primeiro passo precisa ser dado, e ele se apoia em um tripé de ações proativas: educação dos motoboys (com curso de direção defensiva, como determina a atual legislação); orientação dirigida a patrões e consumidores com campanhas de esclarecimento; e fiscalização rigorosa dos órgãos municipais e federais, ligados ao Ministério do Trabalho, sobre as condições de trabalho a que esses profissionais estão submetidos.
\end{abstract}

DESCRITORES: Motocicletas; Acidentes de trânsito; Mortalidade; Mortalidade ocupacional.

\footnotetext{
1. Professor Associado do Departamento de Medicina Legal, Ética Médica e Medicina Social e do Trabalho da Faculdade de Medicina da USP.

2. Professora Assistente da Disciplina de Medicina Legal, Bioética e Perícias Médicas da Faculdade de Medicina do ABC.

3. Professora Titular da Disciplina de Saúde Ocupacional da Faculdade de Medicina do ABC e Professora Assistente do Departamento de Medicina Legal, Ética Médica e Medicina Social e do Trabalho da Faculdade de Medicina da USP

Endereço para correspondência: Instituto Oscar Freire. Rua Teodoro Sampaio, 115. Cerqueira Cesar. São Paulo - Capital. Fone: (11)3061-8408.E-mail: miz@uol.com.br; carmen.miziara@hc.fum.usp.br; lysrocha@usp.br
} 


\section{INTRODUÇ̃̃̃O}

A mortalidade por causas externas no Brasil, a partir da década de 80 do século passado, aumentou de forma exponencial. Em 2002, cerca de $12,87 \%$ do total de óbitos foram devidos a causas externas e, destes, 3,38\% corresponderam a acidentes de transporte ${ }^{1}$.

$\mathrm{Na}$ última década, vem-se observando o aumento crescente do número de acidentes envolvendo motocicletas, veículo que ganha cada vez mais aceitação e aprovação da população, por ser ágil e de baixo custo $^{2}$. Dados publicados pelo Departamento de Informática do Sistema Único de Saúde (SUS) em 2005 mostraram que houve aumento de $79,8 \%$ neste tipo de acidente no período compreendido entre 1997 e $2004^{1}$.

O "Mapa da Violência 2013", referente a acidentes de trânsito envolvendo motocicletas, mostra que em 2010 ocorreram 43.246 óbitos nesta categoria de acidente, o que corresponde a $22,5 \%$ do total de óbitos por acidentes de trânsito no país ${ }^{3}$.

De acordo com os dados do Ministério da Saúde, o custo de internações por acidentes com motociclistas pagas pelo Sistema Único de Saúde (SUS) em 2011 sofreu um aumento de $113 \%$ em comparação com o do ano de 2008, passando de $\mathrm{R} \$ 45$ milhões para $\mathrm{R} \$ 96$ milhões. Este crescimento de gastos foi diretamente associado à elevação do número de internações hospitalares, que passaram de 39.480 para 77.113 no mesmo período. Dados estes que foram caracterizados como epidêmicos ${ }^{4}$.

Especificamente em termos ocupacionais, existem duas categorias básicas de profissionais que utilizam a motocicleta para fins de trabalho: os motoboys e os mototaxistas. Como profissão, ambas são altamente suscetíveis a agravos decorrentes da exposição a acidentes por causas externas e/ou aos agentes físicos, biológicos e psicossociais ${ }^{5}$. Apesar de disseminadas pelas grandes cidades brasileiras, ainda não há registro sobre estas atividades na Classificação Brasileira de Ocupações do Ministério do Trabalho e Emprego ${ }^{4}$. Apenas a de motoboy, segundo a Portaria 397 do Ministério do Trabalho e Emprego, está registrada como ocupação sob o número 5191-10 $0^{6}$. Embora estas atividades sejam semelhantes, o transporte de pessoas é o que difere uma ocupação da outra, pois o mototaxista tem este como sua finalidade principal, afirmam Silva et al ${ }^{5}$.

Em geral, estes trabalhadores executam longas jornadas diárias de trabalho (acima de 10 horas), o que pode acarretar efeitos sobre a saúde e sua qualidade de vida. São comuns entre esses trabalhadores as inversões nos turnos de trabalho, com alternância do ciclo sono-vigília. Seu trabalho é executado sob constante pressão temporal por parte de empregadores e clientes, e a exposição a riscos físicos, químicos, ergonômicos, biológicos, mecânicos e psicossociais, além de trazer agravos à saúde per se, também aumenta o risco de acidentes ${ }^{5,7}$.

Veronesi e Oliveira ${ }^{8}$, por outro lado, afirmam que, na visão dos motociclistas que utilizam o veículo como forma de trabalho, os assim chamados motoboys, os riscos de acidentes, por vezes fatais, ocorrerem é inerente ao tipo de trabalho que executam. Para mototaxistas, os maiores riscos da profissão são os acidentes e os assaltos, nos quais os profissionais podem perder seu "instrumento de trabalho", a motocicleta. Entretanto, para os autores, estes riscos também são considerados inerentes à atividade ocupacional, riscos estes que são justificados por uma possibilidade de ganho financeiro que eles não teriam em outra profissão, devido à sua baixa escolaridade e capacitação ${ }^{8}$.

Para Ganne ${ }^{9}$, as alterações do mercado de trabalho brasileiro nos últimos anos tornaram a motocicleta atraente para a parcela menos capacitada da população. Assim, o desequilíbrio entre a oferta e a procura de vagas de trabalho, sendo a primeira mais reduzida, e a exigência de profissionais cada vez mais capacitados e qualificados fez com que aqueles trabalhadores que não preenchessem este perfil passassem a fazer parte de um mercado paralelo, com atividade econômica informal com finalidade de manter seus proventos?.

Apesar da peculiaridade do perfil profisisonal destes trabalhadores, como descrito acima, de acordo com Veronesi e Oliveira ${ }^{8}$, o aumento do número de motoboys circulando nas ruas das cidades sugere que eles desempenhem importante tarefa, que satisfaçam necessidades sociais contemporâneas e que ingressar na profissão represente uma oportunidade de emprego ${ }^{8}$.

$\mathrm{O}$ aumento das atividades profissionais, formais ou informais, nos setores de serviço de tele-entrega (motoboys) ou de transporte de passageiros (mototaxi) também se associou ao aumento da vitimação destes trabalhadores em decorrência de acidentes ${ }^{7}$. A escassez de uma política municipal responsável (conforme determinação do Conselho Nacional de Trânsito), com consequente falha de fiscalização e de controle desta atividade profissional, contribui para a manutenção de informalidade das relações de trabalho, da mesma forma que se fracassa em prover segurança, expondo os trabalhadores e a população a risco ${ }^{7}$.

\section{OBJETIVO}

O objetivo deste estudo foi, através de revisão da literatura, descrever os principais aspectos dos acidentes de trânsito com motocicletas e sua relação com o trabalho.

\section{MÉTODOS}

Trata-se de estudo descritivo realizado por revisão de literatura dos últimos 10 anos, embora artigos anteriores 
a este período tenham sido incluidos em função de sua relevância, nas seguintes bases de dados de livre acesso: MEDLINE (National Library of Medicine), LILACS (Literatura Latino-americana e do Caribe em Ciências da Saúde), SciELO (Scientific Eletronic Library Online) e Google Acadêmico. Os descritores foram: motocicleta; acidente de trânsito; acidente de trabalho; epidemiologia; mortalidade; e mortalidade ocupacional (em português) e motorcycle; accidents, traffic; occupational accidents; epidemiology; mortality; and occupational mortality (em inglês). Foi realizada pré-análise com base no título dos artigos e leitura dos resumos. A busca por artigos ocorreu entre os meses de setembro de 2012 e abril de 2014. Os critérios de inclusão foram: artigos científicos e publicações disponibilizadas na íntegra, em português, inglês ou espanhol que abordavam as questões relacionadas a acidente de trânsito envolvendo motociclistas. Foram excluidos artigos que se restringiam a acidentes de trânsito de forma geral.

\section{RESULTADOS}

A Organização Mundial de Saúde (OMS) estima que 1,2 milhão de pessoas morram anualmente em acidentes de trânsito e que até 2030 haverá um aumento de $40 \%$ desta taxa de mortalidade ${ }^{10}$. O Brasil poderá contribuir de forma relevante para que esta previsão se concretize caso não sejam adotadas medidas preventivas efetivas e eficazes. Países com grande frota de motocicletas, como Cingapura, apontam altos índices de mortalidade (50\% de todos os acidentes fatais entre os acidentes de trânsito) tanto de pilotos como do passageiro garupa, mostrando a grande vulnerabilidade deste meio de transporte e de trabalho ${ }^{11}$.

Tentativas governamentais tentam minimizar este impacto social e econômico. No Brasil, a Lei $\mathrm{n}^{\circ}$. 12.009, de 29 de julho de 2009, regulamentou a atividade dos profissionais em transporte de passageiros (mototaxistas), em entrega de mercadorias e em serviço comunitário de rua, e motoboys com uso de motocicleta, e determinou que as atividades específicas destes trabalhadores são as de transportar mercadorias compatíveis com a capacidade do veículo e de transportar passageiros. De acordo com a determinação legal, só podem exercer estas atividades de forma regular os profissionais com mais de 21 anos de idade, com no mínimo dois anos de habilitação na categoria e que adotem as medidas de segurança mínimas necessárias ${ }^{12}$. Entretanto, a clandestinidade desta atividade ainda persiste, o que expressa a falha de fiscalização e a consequentemente desproteção dos trabalhadores e da população geral ${ }^{13}$.

A cidade de São Paulo, desde 2008, conta com o Sistema de Informação para a Vigilância de Violências e Acidentes (SIVVA), o qual informa sobre o diagnóstico, o planejamento, o monitoramento e a avaliação das ações de enfrentamento das violências e dos acidentes ${ }^{14}$.

Outras iniciativas preventivas de acidente de trânsito foram adotadas no Brasil nos últimos anos. Em 2010, foi lançado o Projeto "Vida no trânsito", versão brasileira do Road Safety in Ten Countries (ou "RS-10"), financiado pela Fundação Bloomberg e sob a coordenação global da Organização Mundial de Saúde (OMS) e suas agências regionais, com apoio da Organização Panamericana de Saúde (OPAS/OMS no Brasil) e aporte técnico e financeiro do Governo Federal. Este projeto foi desenvolvido em cinco cidades brasileiras (Belo Horizonte, Campo Grande, Curitiba, Palmas e Teresina). Em 2011, o Governo Federal, por meio dos Ministérios da Saúde e das Cidades, lançou o "Parada" - Pacto Nacional pela Redução de Acidentes - Um pacto pela Vida, que tem como objetivo mudar o comportamento da população por meio do desenvolvimento de propostas de educação, legislação, fiscalização, mobilização e promoção para reduzir os acidentes e a violência no trânsito ${ }^{4}$.

Apesar dos projetos serem de grande valor na prevenção de acidentes envolvendo motociclistas, Bacchieri e Barros ${ }^{15}$ entendem que o veto do artigo 56 do Código de Trânsito Brasileiro, que proibia os motociclistas de trafegarem entre veículos de filas adjacentes ou entre a calçada e o veículo, representou maior risco a estes condutores.

\section{Dados epidemiológicos}

De acordo com a National Highway Traffic Safety Administration (NHTSA), agência governamental americana que realiza trabalho de prevenção de lesões e de acidentes relacionados a veículos, em 2007, o crescimento do número de acidentes envolvendo motociclistas foi 34 vezes maior em relação ao de carros e os casos fatais nos últimos 10 anos sofreram um expressivo aumento, passando de 9\% em 2004 para 14\% em $2013^{16}$.

Dados da Compainha de Engenharia de Tráfego (CET) da cidade de São Paulo mostram que a cidade em 2005 tinha 491 mil motocicletas e que, em 2013, este número passou para 995 mil, representando um crescimento de $102,8 \%$. Proporcionalmente, este valor foi expressivamente maior, mais especificamente o triplo, em relação ao crescimento da frota de automóveis, que passou de 4.085 milhões para 5.446 milhões, aumento de 33,3\%. Os dados deste órgão oficial apontam que os acidentes envolvendo motociclistas são graves e com alta taxa de morbimortalidade, sendo que entre 2005 e 2013 houve aumento de $16,8 \%$ de casos fatais ${ }^{17}$.

Estudo realizado entre 1996 e 2007, no Distrito Federal, avaliou as características sociodemográficas de mortalidade de motociclistas em decorrência de acidente de tráfego. Do total de mortes por acidente de trânsito, $7,9 \%$ envolvia motociclista, sendo que 94,3\% destas vítimas eram homens. A comparação de mortes durante 
o transcorrer do período avaliado mostrou aumento, passando de 25 eventos em 1996 para 139 em 2007. O sábado foi o dia da semana com maior proporção de casos fatais $(17,4 \%)$, em segundo lugar veio a terça-feira, a maioria das mortes foi em hospitais $(73,6 \%)$, embora as mortes nas vias públicas tenham apresentado elevação, passando de $14,7 \%$ em $2000-2003$ para $29,8 \%$ em $2004-$ $2007^{18}$.

Outros estudos mostraram que grande parte dos acidentes $(37,4 \%)$ ocorreu durante o dia (das 7 às 18 horas $)^{9,19,20}$ e cerca de $80 \%$ destes acidentes aconteceram nos dias úteis da semana e em dias secos, de acordo com os resultados de Soares et $\mathrm{al}^{20}$.(2011).

Silva et al. ${ }^{21}$ avaliaram o perfil demográfico de 750 motociclistas couriers de duas cidades do estado do Paraná - Maringá e Londrina. Deste total, 31,7\% relataram envolvimento em acidente de trânsito nos últimos 12 meses que precederam a pesquisa e com gravidade em aproximadamente $11 \%{ }^{21}$. O perfil desta população estudada era formado predominantemente por homens, com baixo nível de instrução escolar e reduzido tempo de profissão. Dentre o grupo de trabalhadores, a maioria $(48 \%)$ trabalhava no ramo de transporte de alimentos (pizzarias, lanchonetes e restaurantes), 26,8\% em farmácias e drogarias, $23,9 \%$ em empresas de entregas e 11,4\% faziam entrega de água. Neste estudo foi descrito que apenas um pouco mais da metade $(52,8 \%)$ dos entrevistados utilizavam capacetes do tipo aberto, importante parcela $(84,4 \%)$ referiu dirigir em situações de cansaço físico (jornadas acima de 10 horas diárias), e, o mais alarmante, 34\% afirmaram já ter feito consumo prévio de álcool antes de dirigir. Para os autores, o cansaço físico e mental causado pela sobrecarga, a alternância de turnos e jornadas superiores há 10 horas diárias foram os principais facilitadores de acidentes de trabalho entre estes profissionais, por causarem diminuição de reflexos e de atenção ${ }^{7}$.

Miki et al. ${ }^{22}$ descreveram 381 motociclistas vitimados por acidente de trânsito. A maioria era masculina (85\%) e jovem (30,7 anos em média) e 75,5\% das lesões acometeram os membros inferiores, das quais $95,4 \%$ necessitaram de tratamento cirúrgico. Os principais mecanismos de acidentes foram as colisões $(46 \%)$ e as quedas $(43 \%)^{22}$. Este perfil de vítimas também foi objeto de conclusão de outro estudo recente, que mostrou o predomínio de homens $(81,6 \%)$ jovens (20 e 24 anos) dentres os envolvidos em acidente de motocicleta ${ }^{19}$.

Segundo Bachieri e Barros $^{15}$, a mortalidade de passageiros e condutores de motocicleta teve aumento de $700 \%$ no período compreendido entre 1998 e 2008, passando de 1.028 para 8.529 vítimas fatais.

\section{Fatores de risco para acidentes fatais e riscos profissionais}

A correlação entre o risco de acidentes envolvendo motoboys e a ocupação das vítimas foi estudada por Veronese e Oliveira ${ }^{8}$. Os autores concluíram que os motoboys têm consciência dos riscos da profissão e associam estes riscos às condições do trabalho, à urgência de completar as demandas exigidas pelo patrão, à competição entre os motoboys e ao cansaço, isto é, à sobrecarga de trabalho exigida. Também se associam a estes fatores a experiência, a imprudência na condução do veículo, as condições climáticas, (chuva) e a má sinalização do sistema viário ${ }^{8}$. Em seguimento a este cenário, é possível concluir que a atividade laborativa do motociclista envolve questões do piloto e da dinâmica de trabalho imposta pelo empregador ${ }^{7}$. Para vários autores, as exigências do trabalho (pressão exercida pelos patrões e pelos clientes para que as entregas sejam realizadas com rapidez, associadamente à remureação, que é atrelada à produtividade, as jornadas prolongadas e o estresse psicológico) representam o principal fator de risco de acidente de trabalhadores que utilizam a motocicleta como meio de trabalho $0^{7,8,23-25}$.

Além dos acidentes e do ritmo extenuante de trabalho, foram apontados pelos mototaxistas a vulnerabilidade a assaltos, o sedentarismo, os distúrbios de sono e a irritabilidade. Silva et al. ${ }^{5}$. Outra questão levada em consideração foi o risco de acidente grave, muitas vezes fatal, causado por linha com cerol, segundo Ladeira et al. ${ }^{26}$.

Amorin et al. ${ }^{25}$,através de análise de uma população de mototaxistas, mostraram que houve associação direta entre a quantidade de dias de trabalho por semana, a presença de fadiga em membros inferiores, especialmente no final do dia, e as queixas musculoesqueléticas com os acidentes de trabalho. No grupo estudado, a referência de jornada de trabalho de seis a sete dias por semana foi de $92,1 \%$ dos participantes e a de duração de oito horas ou mais por dia foi de $82,8 \%{ }^{25}$.

\section{Acidente de trabalho}

No Estado de São Paulo, entre 1997 a 1999, a distribuição de acidentes do trabalho, segundo agrupamentos criados e tipo de acidente, mostrou, entre os motociclistas: $9,9 \%$ de acidentes típicos; $22,6 \%$ de acidente de trajeto e $1,1 \%$ de doença ocupacional ${ }^{27}$.

Em Joinville (SC), Pereira e Fischer ${ }^{28}$ entrevistaram 78 motociclistas que haviam sofrido acidente, sendo $74,36 \%$ caracterizados como acidentes de trajeto e $25,64 \%$ como acidentes típicos. Em 80,7\% dos casos os motociclictas eram do sexo masculino e $74,39 \%$ deles eram jovens de até 32 anos. Em 48,72\% dos acidentes os membros inferiores foram os mais atingidos por lesões; $79,92 \%$ dos trabalhadores pesquisados possuíam registro em carteira profissional e em 51,28\% dos acidentes não foi emitida a comunicação de acidente de trabalho (CAT). Desta população analisada, 39,74\% utilizava ou 
permanecia com auxílio do Instituto Nacional do Seguro Social (INSS) e, no período estudado, três deles foram a óbito ${ }^{28}$.

Duarte ${ }^{29}$ utilizou como fonte o banco de dados do Sistema de Informação em Acidentes de Trabalho do SUS de Belo Horizonte (SIAT-SUS/BH) no período de 2004 a 2008 e descreveu que o perfil dos acidentados era na maioria composto por homens $(91 \%)$ jovens $(65 \%)$, de faixa etária variando de 20 a 29 anos. Do total de dados analisados, a autora observou que $33,2 \%$ dos motociclcistas exerciam a profissão para o transporte de documentos e de pequenos volumes ${ }^{29}$.

Estudo conduzido em Londrina e Maringá (PR) analisou 327 motoboys vítimas de acidentes motociclísticos no perído de 2005 e 2006 e concluiu que: $39,6 \%$ dos entrevistados se envolveram mais de uma vez em acidentes de trânsito, sendo que os acidentes foram considerados graves por $21,4 \%$ dos participantes e $56,3 \%$ relataram conhecer algum motoboy que estava afastado do trabalho em decorrência de acidente. Um dado expressivo foi de que a maioria dos acidentes $(82,9 \%)$ ocorreu durante o trabalho, inclusive $10 \%$ dos entrevistados já haviam sofrido quatro ou mais acidentes durante o trabalho com motocicleta?

Amorim et al. $^{25}$ entendem que o processo de trabalho dos mototaxistas está diretamente relacionado à maior incidência de acidentes. As ruas passaram a ser o espaço de trabalho destes profissionais, com consequente maior exposição ao risco. Os autores analisaram 267 profissionais entre os 300 cadastrados na Superintendência Municipal de Transportes e Trânsito (SMTT) e concluíram que, no grupo estudado, a incidência anual de acidentes de trabalho envolvendo mototaxistas foi de $10,5 \%$, sendo que as lesões foram leves em $48,7 \%$ dos acidentados, mas $27 \%$ das vítimas foram obrigadas a se afastar das atividades laborais no período em que se encontravam lesionadas ${ }^{25}$.

Duarte $^{29}$, analisando o banco de dados do SIATSUS/BH, notou que comércio foi o ramo de atividade econômica que apresentou o maior número de acidentes de trabalho, e o código do ramo da atividade do comércio que apresentou a maior frequência foi o de atividades de investigação, vigilância e segurança. $\mathrm{O}$ acidente de trabalho de trajeto liderou o tipo de acidente ${ }^{29}$.

\section{Circunstâncias e tipos de lesão}

Estudo conduzido na Malásia ${ }^{30}$ mostrou que os traumatimos cranianos e as lesões no pescoço foram as formas de lesões mais mortais dentre as apresentadas por motociclistas.

Pesquisa realizada na Califórnia envolvendo pilotos de motocicleta constatou que a falta ou o uso indevido de capacetes, a ejeção vítima, os efeitos de álcool ou outras drogas, as colisões envolvendo caminhão eram as situações mais propensas a resultar ferimentos fatais, independentemente da faixa etária ${ }^{32}$. O uso de capacete foi fator de proteção de lesão facial, determinada pela Escala de Gravidade de Lesão Facial, conforme estudo brasileiro realizado com 253 motociclistas vítimas de lesão craniofacial em que foi comparada a gravidade de lesão dentre aqueles que usavam e os que não usavam capacete no momento do trauma ${ }^{33}$. As lesões em membros inferiores são as mais frequentemente encontradas em acidentes envolvendo motocicletas ${ }^{29}$.

Quanto ao tipo de acidente, mais da metade deles se deu em colisão contra outro veículo, variando entre 59,5\% e $65,6 \%$, conforme resultado de estudo conduzido em duas cidades do Paraná, Maringá e Londrina, respectivamente ${ }^{5}$.

Soares et al. ${ }^{20}(2011)$ entrevistaram 327 motoboys. Destes, 39,6\% relataram mais de um acidente de trânsito e sendo que $82,9 \%$ deles ocorreram durante a jornada de trabalho. Neste grupo, os acidentes foram percebidos como graves por $21,4 \%$ dos entrevistados e $56,3 \%$ deles relataram conhecer motoboy afastado do trabalho por acidente $^{20}$.

\section{DISCUSSÃO}

A motocicleta, no Brasil e em vários países do mundo, é um meio de transporte socialmente importante, especialmente para a classe trabalhadora que a utiliza como meio de prestação de serviços como mototaxi, motoboy ou motofrete. Um dos fatores que fomentaram a expansão da frota de motocicleta foi o custo acessível do veículo, com formas de pagamento facilitadas por planos de longo prazo $^{5}$. Com o aumento do uso da motocicleta como forma de transporte e ferramenta de trabalho, houve um aumento exponencial de morbimortalidade por acidentes. De acordo com os dados do Departamento Nacional de Trânsito (Denatran), entre 1998 e 2011 a taxa de mortalidade de motociclistas oscilou de um mínimo de 67,8 mortes/100 mil motociclistas em 1998 e um máximo de 101,1 mortes/100 mil motociclistas em 2002, com uma média de 91 óbitos por 100 mil motocicletas registradas. A frota de motocicletas cresceu $491 \%$ no período e as mortes de motociclistas cresceram $610 \%$; estes dados sugerem que o aumento da taxa de mortalidade não se deu apenas pelo aumento da frota (responsável por 491\% do incremento da mortalidade), mas os $119 \%$ (diferença entre ambas as porcentagens) representa também um aumento de morte de motociclistas no trânsito ${ }^{3}$.

Um dos fatores do crescimento desse tipo de trabalho decorre da mudança no processo produtivo, com expressiva alteração no padrão de mercado de trabalho brasileiro, com menor oferta de vagas e maior exigência de qualificação profissional. Desta forma, surgiu um mercado paralelo de atividades econômicas informais, ocupado por indivíduos que, sem outra opção, buscam a sobrevivência no setor de serviços como as atividades desempenhadas pelos denominados motoboys ou mototaxistas9.

A informalidade é um dos motivos que dificulta a caracterização de acidentes de trabalho envolvendo 
motocicletas. Também deve ser considerado o fato de a lei que regulamenta a profissão de motoboy e mototaxista ser recente, surgida em $2009^{8}$. Como, até pouco tempo atrás, a profissão não era reconhecida como tal, há poucos trabalhos abordando os riscos inerentes à própria ocupação.

Nosso estudo apresentou uma fraqueza específica: poucos estudos relacionam a profissão de motoboys e mototaxistas e as condições de trabalho, incluindo aí acidentes de trabalho. Ficou claro, entretanto, na literatura revisada, que os acidentes envolvendo motocicletas, principalmente quando relacionados a motoboys e mototaxistas, são caracterizados como acidentes de trabalho. Esse tipo de problemática é relativamente nova em nossa sociedade, inclusive porque a regulamentação da profissão de motoboy e de mototaxista tem pouco mais de meia década e são poucos os estudos que abordam a questão de maneira abrangente e com casuística representativa da população brasileira. Somente com dados epidemiológicos consistentes será possível estabelecer uma política multidisciplinar e multissetorial preventiva eficaz e eficiente visando a prevenção e a promoção da saúde destes trabalhadores ${ }^{8,15}$. Seria muito simplista direcionar a responsabilidade desta realidade a fatores intrínsecos da profissão, mas também é preciso considerar o perfil do profissional e da sociedade em geral. A violência no trânsito não é restrita aos motociclistas (motoboys ou mototaxistas).

Há de se acrescentar aqui também a violência no trânsito das grandes cidades como fator agravante, principalmente quando se leva em conta o pouco respeito que parte dos condutores de veículos de quatro rodas tem para com os motociclistas, ensejando muitas vezes acidentes que pouco têm a ver com o comportamento do motoboy ou do mototaxista. Desse modo, acreditamos que o primeiro passo precisa ser dado, e ele se apoia em um quarteto de ações proativas: educação dos motoboys (com curso de direção defensiva, como determina a atual legislação); orientação dirigida a patrões e consumidores com campanhas de esclarecimento; fiscalização rigorosa dos órgãos municipais e federais, ligados ao Ministério do Trabalho, sobre as condições de trabalho a que esses profissionais estão submetidos; e medidas educativas para os condutores de veículos de quatro rodas acerca do respeito que devem ter para com os condutores de motocicletas.

\section{CONCLUSÕES}

O crescimento da frota de motocicletas e o surgimento galopante de uma atividade profissional caracterizada pelos motoboys e mototaxistas nas últimas décadas foram acompanhados de alta taxa de mortalidade. Embora a literatura médica não mostre uma abrangência nacional, os dados descritos foram claros quanto à determinação de relação direta entre o acidente e o trabalho. A subnotificação deste evento, principalmente por se tratar de atividade informal, na grande maioria, provavelmente é realidade. As vítimas de acidentes em geral sofrem lesões em seguimentos dos membros inferiores, mas a mortalidade está, muito provavelmente, ligada ao politraumatismo e ao traumatismo cranioencefálico. A maioria dos estudos mostra que as vítimas mais frequentes são homens jovens e com baixo nível de instrução acadêmica e que encontraram nesta fatia do mercado a oportunidade de obter proventos, mercado de trabalho este ainda caracterizado pela informalidade.

Miziara ID; Miziara CSMG; Rocha LE. Motorcycle accidents and its relation to work: a literature review. Saúde, Ética \& Justiça. 2014;19(2):52-9.

\begin{abstract}
In the last decade, the number of accidents involving motorcycles has greatly increased in Brazil. The Motorcycle has been gaining growing acceptance and approval due to its advantages in traffic and low cost. Objective: The aim of this study was, through a literature review, to describe the main aspects of traffic accidents with motorcycles and their relationship with work. Method: This is a descriptive study by way of a literature review using the major databases of open access. Inclusion criteria were scientific articles and publications of the past 10 years. The selected texts were in English, Portuguese and Spanish and the descriptors used were: motorcycle, traffic accident, accident at work, epidemiology, mortality and occupational mortality. Results: the Motorcycle is a socially important vehicle in Brazil, especially for the working class, which uses it for their own transportation or as a means of providing services such as those of motorcycle-taxis, motorcycle couriers or delivery motorcycles. Victims of accidents involving motorcycles are mostly male, aged 20-30 years old. Most of them are individuals with a low level of education for whom working as motorcycle couriers and motorcycle taxi drivers seems to be an opportunity to enter the labor market. The majority of professional motorcycle drivers' jobs consist of transporting food or delivering drugs for drugstores. As risk factors, the authors identified: use of helmets open type; high exposure to all kinds of risk factors (physical, chemical, psychosocial); driving in situations of physical and mental fatigue, prior consumption of alcohol, more than 10 hours daily journeys. Bikers not always had job registry documents and in few cases the accidents were reported as work related. On weekends, there were proportionally more accidents. Conclusion: Few studies in Brazil address aspects of the work of motorcycle drivers. However, we believe that, as a first step, measures must be taken based on proactive actions: education of couriers (with defensive driving course, as required by current law); guidance made available for employers and consumers through information campaigns; and strict enforcement related to the conditions of work experienced by these professionals carried out by municipal and federal agencies, linked to the Ministry of Labour.
\end{abstract}

KEY WORDS: Motorcycles; Accidents, traffic; Mortality, Occupational Mortality. 


\section{REFERÊNCIAS}

1. Santos AMR, Moura MEB, Nunes BMVT, Leal CFS, Teles JBM. Perfil das vítimas de trauma por acidente de moto atendidas em um serviço público de emergência. Cad Saude Publica. 2008;24(8):1927-38. DOI: http://dx.doi. org/10.1590/S0102-311X2008000800021

2. Oliveira NLB, Sousa RMC. Diagnóstico de lesões e qualidade de vida de motociclistas, vítimas de acidentes de trânsito. Rev Lat Am Enfermagem. 2003;11(6):749-56. DOI: http://dx.doi.org/10.1590/S0104-11692003000600008

3. Waiselfisz JJ. Mapa da Violência 2013. Acidentes de trânsito e motocicletas. Rio de Janeiro: CEBELA (Centro Brasileiro de Estudos Latino-Americanos); 2013.

4. Portal Brasil. Acidentes de trânsito envolvendo motociclistas supera o de pedestres e motoristas [Internet]. Brasília, DF; 2012 [2012 jun 20; acesso em 2015 mai 22]. Disponível em: http://www.brasil.gov.br/economia-e-emprego/2012/06/ acidentes-de-transito-com-motociclistas-supera-o-depedestres-e-motoristas

5. Silva MB, Oliveira MB, Fontana RT. Atividade do mototaxista: riscos e fragilidades autorreferidos. Rev Bras Enferm. 2011;64(6):1048-55. DOI: http://dx.doi. org/10.1590/S0034-71672011000600010

6. Brasil. Ministério do Trabalho e Emprego. Portaria $\mathrm{n}^{\circ}$ 397 de 09 de Outubro de 2002. Aprova a Classificação Brasileira de Ocupações - CBO/2002, para uso em todo território nacional e autoriza a sua publicação [Internet]. Brasília, DF; 2002 [2002 out 09; acesso em 2014 mai 30]. Disponível em: http://www.mtecbo.gov.br/cbosite/pages/ legislacao.jsf

7. Silva DW, Andrade SM, Soares DA, Soares DFPP, Mathias TAF. Perfil do trabalho e acidentes de trânsito entre motociclistas de entregas em dois municípios de médio porte do Estado do Paraná, Brasil. Cad Saude Publica. 2008;24(11):2643-52. DOI: http://dx.doi.org/10.1590/ S0102-311X2008001100019

8. Veronese AM, Oliveira DLLC. Os riscos de acidentes de trânsito na perspectiva dos moto-boys: subsídios para a promoção da saúde. Cad Saude Publica. 2006;22(12):2717-21. DOI: http://dx.doi.org/10.1590/ S0102-311X2006001200021

9. Ganne N. Estudo sobre acidentes de trânsito envolvendo motocicletas, na cidade de Corumbá e região, Estado de Mato Grosso do Sul, Brasil, no ano de 2007. Rev Pan-Amaz Saude. 2010;1(3):19-24. DOI: http://dx.doi.org/10.5123/ S2176-62232013000100003

10. World Health Organization. The global impact. Chapter 2. In: Peden M, Scurfield R, Sleet D, Mohan D, Hyder AA, Jarawan E, Mathers C, editors. World report on road traffic injury prevention. Geneva: World Health Organization; 2004. p.33-61.

11. Chiang VXY, Cheng JYX, Zhang ZC, Teo LT. Comparison of severity and pattern of injuries between motorcycle riders and their pillions: A matched study. Injury. 2014;45(1):333-

\section{DOI: http://dx.doi.org/10.1016/j.injury.2013.01.040}

12. Brasil. Presidência da República/Casa Civil. Lei $n^{\circ} 12.009$, de 29 de julho de 2009. Regulamenta o exercício das atividades dos profissionais em transporte de passageiros, "mototaxista", em entrega de mercadorias e em serviço comunitário de rua, e "motoboy", com o uso de motocicleta, altera a Lei no. 9.503, de 23 de setembro de 1997, para dispor sobre regras de segurança dos serviços de transporte remunerado de mercadorias em motocicletas e motonetas moto frete -, estabelece regras gerais para a regulação deste serviço e dá outras providências. Diário Oficial da União, Brasília, DF; 2009.

13. Barbosa KGN, Lucas-Neto A, Gama BD, Lima-Neto JC, Lucas RSCC, d'Ávila S. Injuries and absenteeism among motorcycle taxi drivers who are victims of traffic accidents. J Forensic Leg Med. 2014;26:15-8. DOI: http://dx.doi. org/10.1016/j.jflm.2014.03.008

14. Prefeitura da Cidade de São Paulo. Secretaria Municipal da Saúde. Sistema de Informação para a Vigilância de Violência e Acidentes - SIVAA: Manual de Preenchimento da Ficha de Notificação de Casos Suspeitos ou Confirmados [Internet]. São Paulo, SP; 2007 [acesso em 2015 mai 22]. Disponível em: http:/www.prefeitura.sp.gov.br/cidade/ secretarias/upload/08_09_10_manual_sivva_1254424639. pdf

15. Bacchieri G, Barros AJD. Acidentes de trânsito no Brasil de 1998 a 2010: muitas mudanças e poucos resultados. Rev Saude Publica. 2011;45(5):949-63. DOI: http://dx.doi. org/10.1590/S0034-89102011005000069

16. United States Department of Transportation. National Highway Traffic Safety Administration - NHTSA. National Center for Statistics and Analysis. Traffic Safety Facts - Research Note. 2013 Motor Vehicle Crashes: Overview [Internet]. Washington; 2014 [acesso em 2015 mai 22]. Disponível em: http://www-nrd.nhtsa.dot.gov/ Pubs/812101.pdf

17. De Paula MEB (Companhia de Engenharia de Tráfego de São Paulo). Nota Técnica 232: Evolução do número de mortes no trânsito em São Paulo [Internet]. São Paulo, SP; 2014 [acesso em 2015 mai 23]. Disponível em: http://www. cetsp.com.br/media/294272/nt_232.pdf

18. Montenegro MMS, Duarte EC, Prado RR, Nascimento AF. Mortality of motorcyclists in traffic accidents in the Brazilian Federal District from 1996 to 2007. Rev Saude Publica. 2011;45(3):529-38. DOI: http://dx.doi. org/10.1590/S0034-89102011000300011

19. Rodrigues CL, de Eston Armond J, Gorios C, Souza PC. Accidents involving motorcyclists and cyclists in the municipality of São Paulo: characterization and trends. Rev Bras Ortop. 2014;49(6):602-6. DOI: http://dx.doi. 
org/10.1016/j.rboe.2014.11.002

20. Soares DFPP, Mathias TAF, Silva DW, Andrade SM. Motociclistas de entrega: algumas características dos acidentes de trânsito na Região Sul do Brasil. Rev Bras Epidemiol. 2011;14(3):435-44. DOI: http://dx.doi. org/10.1590/S1415-790X2011000300008

21. Silva DW, Andrade SM, Soares DFPP, Mathias TAF, Matsuo T, Souza RKT. Factors Associated with Road Accidents among Brazilian Motorcycle Couriers. ScientificWorldJournal. Volume 2012, Article ID 605480, 6 pages. DOI: http://dx.doi.org/10.1100/2012/605480

22. Miki N, Martimbianco ALC, Hira LT, Lahoz GL, Fernandes HJA, Reis FB. Profile of trauma victims of motorcycle accidents treated at hospital São Paulo. Acta Ortop Bras. 2014;22(4):219-22. DOI: 10.1590/141378522014220400642

23. Diniz EPH, Assunção AA, Lima FPA. Por que os motociclistas profissionais se acidentam? Riscos de acidentes e estratégias de prevenção. Rev Bras Saude Ocup. 2005;30(111):41-50. DOI: http://dx.doi.org/10.1590/ S0303-76572005000100006

24. Mascarenhas MDM, Malta DC, Silva MMA, Carvalho CG, Monteiro RA, Morais Neto OL. Consumo de álcool entre vítimas de acidentes e violências atendidas em serviços de emergência no Brasil, 2006 e 2007. Cien Saude Coletiva. 2009;14(5):1789-96. DOI: 10.1590/S141381232009000500020

25. Amorim CR, Araujo EM, Araujo TM, Oliveira NF. Acidentes de trabalho com mototaxistas. Rev Bras Epidemiol. 2012;15(1):25-37. DOI: http://dx.doi. org/10.1590/S1415-790X2012000100003

26. Ladeira RM, Carreiro PRL, Rezende-Neto JB, Iannuzzi GC, Elias AA. Epidemiologia dos acidentes provocados por linhas com cerol: estudo de vítimas atendidas em hospital de trauma em Belo Horizonte, Brasil. Rev Bras Epidemiol.
2012;15(2):407-14. DOI: http://dx.doi.org/10.1590/S1415790X2012000200018

27. Teixeira MLP. Acidentes e doenças do trabalho de profissionais do setor transporte: análise dos motoristas no Estado de São Paulo, 1997 a 1999 [dissertação]. São Paulo: Faculdade de Saúde Pública, Universidade de São Paulo; 2005. Disponível em: http://bvsms.saude.gov.br/ bvs/trabalhador/pdf/dissertacao_monica_teixeira.pdf

28. Pereira AA, Fischer GJ. Acidentes de trabalho com motocicleta em Joinville, SC. Revista Saude e Ambiente. 2009;10(2):71-81.

29. Duarte MEL. Análise dos acidentes de trabalho causados por meio de transporte motocicleta em uma capital brasileira [dissertação]. Belo Horizonte: Escola de Enfermagem, Universidade Federal de Minas Gerais; 2011. Disponível em: http://www.enf.ufmg.br/site_novo/modules/mastop_ publish/files/files_4dd11182acfd3.pdf

30. Ramli R, Oxley J, Noor FM, Abdullah NK, Mahmood MS, Tajuddin AK, McClure R. Fatal injuries among motorcyclists in Klang Valley, Malaysia. J Forensic Leg Med. 2014;26:39-45. DOI: http://dx.doi.org/10.1016/j. jflm.2014.06.007

31. Kashani AT, Rabieyan R, Besharati MM. A data mining approach to investigate the factors influencing the crash severity of motorcycle pillion passengers. J Safety Res. 2014;51:93-8. DOI: http://dx.doi.org/10.1016/j. jsr.2014.09.004

32. Jung S, Xiao Q, Yoon Y. Evaluation of motorcycle safety strategies using the severity of injuries. Accid Anal Prev. 2013;59:357-64. DOI: http://dx.doi.org/10.1016/j. aap.2013.06.030

33. Albuquerque CEL, Arcanjo FPN, Cristino-Filho G, LopesFilho AMA, Almeida PC, Prado R, Pereira-Stabile CL. How Safe Is Your Motorcycle Helmet? J Oral Maxillofac Surg. 2014;72(3):542-9. DOI: http://dx.doi.org/10.1016/j. joms.2013.10.017 